\title{
Phenotyping of Sorghum Lines for Resistance to African Stem Borer (Sesamia Calamistis)
}

\author{
Evilla Badiru* \\ National Biotechnology Development Agency, P.M.B 5118.Wuse.Abuja, Nigeria \\ Mary Yeye \\ Institute for Agricultural Research, Ahmadu Bello University, Zaria
}

\begin{abstract}
Stem borer (Sesamia calamistis) is a serious insect pest of sorghum (Sorghum bicolor) resulting in grain yield losses ranging between 15-80\%. However, genotypes showing complete resistance to these borers have not been identified in Nigeria. Utilization of resistant varieties in combination with other methods of control would offer a sustainable strategy for $S$. calamistis management in sorghum production. The objective of this study was to validate the acclaimed resistance in the materials received from Kenya and India in Nigerian environment and to screen and ascertain the status of some Nigerian Sorghum to Sesamia calamistis. Eighty-eight sorghum lines were artificially infested with the eggs of the stem borers at two different environment (Field and Screen House) using alpha-lattice design, consisting of 11 plots in eight blocks, replicated twice. Data were collected on leaf feeding, number of dead-hearts, cumulative stem tunnel length, number of exit holes, and selected agronomic traits. There were significant $(\mathrm{p}<0.01)$ differences among the test genotypes for all the traits measured. Based on the selection index, $15 \%$ of genotypes were categorized as resistant, $42 \%$ as moderately resistant,33 as moderately susceptible and $10 \%$ as susceptible.13 genotypes showed resistance across the environments (field and screen house): ICSB464, ICSL71086, SSV20041-2YELLOW, ICSL71018, ICSR94032, ICSV700, ICSL71193, ICSR94030, ICSL71253, ICSL71268, ICSL71023, ICSL71061 and ICSL71137 were resistant with selection index ranging from 0.0 to 0.5 . These sorghum lines with various resistance to $S$. calamistis could be used as source of resistance and as parents in sorghum improvement programme in breeding for resistance to stem borer.
\end{abstract}

Keywords: Genotypes, novel source of resistance, Sesamia calamistis, Sorghum bicolor

DOI: $10.7176 / \mathrm{JBAH} / 11-18-04$

Publication date:September $30^{\text {th }} 2021$

\section{Introduction}

Sorghum [Sorghum bicolor (L.) Moench] is an important food crop and ranks fifth after wheat, rice, maize, and barley in total area of production globally (Kuhlman, et al., 2010). Nearly 80\% of the cultivated area lies in Asia and Africa and widely cultivated for food, forage, ethanol, and sugar production (Liu et al., 2009). Sorghum production especially in tropical Africa is curtailed by a number of important anthropod pests, with the stem borers belonging to lepidoptera being the most important. Stem borers cause grain yield losses ranging from 15$80 \%$ depending on crop variety, phenological stage and agro ecological environment (Karaya et al., 2009, Muturi et al., 2012). The damage caused are leaf feeding, dead heart formation, exit holes and stem tunneling damage (Kishore et al., 2007; and Muturi et al., 2012). The spotted stem borer (Chilo partellus (Swinhoe)) Pyralidae, African stem borer (Busseola fusca Fuller), and African pink borer (Sesamia calamistis) are among the most damaging insect pests that greatly reduce sorghum grain yield in African environments (Sharma et al., 2005; Mwimali et al., 2015). Among the several stalk borer species, pink stem borer (Sesamia calamistis (Hampson)) is the most important pest of sorghum in the Nigerian savannah (Ajayi 1998, Anaso and Thilza, 2006). Grain yield loss of about 49\% was reported in Nigeria (Ajayi 1991., Ajayi 1997). Total crop failure had also been reported in a few instances (Emmanuel and Chinwe, 2008). There is, however, limited germplasm with resistance to these pests. Several options for managing sorghum borers have potential to mitigate their damaging effects, but each option has its own limitations. Host plant resistance forms an important part of integrated pest management as it provides inherent control without environmental issues and is compatible with other pest management approaches (Singh et al., 2012). Effective breeding methods for resistance to borer damage could, therefore, be designed by plant breeders using both improved and new sources of stem borer resistance.

Management of $S$. calamistis in sorghum has mainly focused on cultural control, burning of crop residues, intercropping and predominantly the use of pesticides (Amsalu et al., 2008). However, use of these strategies would invariably increase the cost of cultivation of sorghum, which is not a feasible option for the resource poor farmers of the semi-arid tropics. Furthermore, the use of chemical pesticides could be harmful to both the environment and human health. Hence, the exploitation of host plant resistance is the only viable option both in terms of economic and environmental sustainability for controlling stem borer in sorghum (Tadele et al., 2011). Considering multiple stem borer damage traits are useful since resistance to stem borers is quantitatively 
inherited thus selecting for resistance based on a single parameter would not be effective. Although there have been some success through conventional breeding approaches in improving plant resistance to stem borer, but only low to moderate levels of resistance have been observed in the cultivated germplasm (Singh et al., 2011) and the identified resistant sources in germplasm possess many undesirable agronomic characters (Singh and Rana, 1986).

High yielding varieties in Nigeria are susceptible to stem borers. Thus, there is the need to increase the levels of tolerance in elite genotypes without sacrificing grain and Stover yield. Much of the existing sorghum germplasm in Africa and Asia have not been evaluated for resistance to stem borers (Dhillon and Sharma, 2012). Therefore, it is important to identify sorghum genotypes with high levels of resistance and diversify the bases of resistance through screening more germplasm (Singh et al., 2011). In Nigeria, little research attention has been accorded to stem borers like $S$. calamistis in cereals and there is paucity of information on the status (resistance/susceptibility) of the elite sorghum germplasm. Screening of all the elite germplasm becomes necessary in the present investigation as the first phase of resistance breeding programme. Such information will be useful in developing an appropriate strategy to produce stem borer-resistant open pollinated varieties and hybrids for cultivation by the farmers in the semi-arid tropics. Therefore, the objective of this study was to assess the levels of resistance of elite sorghum germplasm obtained from ICRISAT Kenya and India and Institute for Agricultural Research (IAR) released sorghum varieties.

\section{MATERIALS AND METHODS Experimental Sites}

The research was conducted at the IAR screen house and research farm at Samaru, Zaria. Nigeria. The farm is located on $11^{\circ} 11^{\prime} \mathrm{N}, 7^{\circ} 38^{\prime} \mathrm{E}, 640 \mathrm{~m}$ asl, $1200 \mathrm{~mm}$ annual rainfall) in the Northern Guinea Savannah.

\section{Experimental Procedures}

Eighty-eight sorghum lines comprising forty recombinant inbred lines (RILs) from ICRISAT Nairobi, Kenya, eight varieties from ICRISAT Patancheru, India, twenty-eight elite germplasm lines from Nigeria and twelve IAR released varieties. These lines were planted in IAR research farm under rain-fed condition. These lines were arranged in an alpha-lattice design, consisting of 11 plots in eight blocks, replicated twice. Each plot consisted of a row, $5 \mathrm{~m}$ long; the inter and intra row spacing was $75 \mathrm{~cm}$ and $30 \mathrm{~cm}$, respectively. Three seeds were planted and later thinned to two plants per stand after two weeks of sowing. At 16 days after sowing, the crops were sprayed with cypermethrin (synthetic pyrethroid) to minimize shoot fly infestation, since this insect interferes with screening for resistance to stem borers (Makueti et al., 2012).

\section{Field and Screen House Validation for Stem Borer Resistance Status}

Twenty one days after sowing, plants were artificially infested with $50 \mathrm{~g}$ of stem borer eggs placed between the stem and the last unfolded leaf sheath using a forcep. Eggs of $S$. calamistis used in this study were obtained from the International Institute for Tropical Agriculture (IITA) Ibadan. To avert drowning of eggs in the water held in leaf whorls, sorghum seedling whorls were tapped gently before infestation. Infestations were carried out early in the morning to encourage egg survival. All other recommended cultural practices were observed. At the screen house, the same source of eggs of $S$. calamistis used on the field were used. One sorghum line/variety was sown in one pot repeated twice. Three seeds were planted and later thinned to two plants per pot after 2 weeks of sowing. Infestation was carried out as described for field above.

\section{Parameters scored for Stem borer damage}

On the field, 4 plants within each row were tagged for infestation while in the screen house two plants per pot were sampled and data were taken systematically from the marked plants. The observations were recorded on per plant basis at two and four weeks after the artificial infestation. Percentages of plants with leaf damage were computed by expressing the number of plants showing pinholes damage as a percentage of the total number of plants sampled (Muturi et al., 2012). Dead heart incidence was computed by counting the number of plants showing dead heart damage and expressed as a percentage of the total number of plants sampled (Kumar et al., 2005). At harvest, numbers of stem borer exit holes on the stem were counted on each sampled plant. The main stem of plants infested was split open from the base to the apex, and the cumulative tunnel length measured with a ruler in centimeters. Seedling vigour was scored at 2 weeks after sowing on a scale of $1-5$, where $1=$ low vigour (plants showing minimum growth, less leaf expansion and poor adaptation; 3=Moderate vigor; 5=high vigor tall plants with expanded leaves and robustness) (Kishore et al., 2007, Muturi et al., 2012). At physiological maturity, plant height was measured in centimeter from the base of the plant to the tip of the panicle using a calibrated pole. Days to panicle emergence was recorded as the number of days from the date of sowing to the date when $50 \%$ of panicle emerged in a plot. Days to $50 \%$ flowering was recorded as the number of days from the date of sowing to the date of anthesis of $50 \%$ of plants in a plot. After harvest, sorghum 
panicles were sun-dried and hand threshed. Grain yield and hundred seed weight were recorded in grams for each of the sampled plants using an electric weighing balance.

\section{Statistical Analysis}

Data were first analyzed on individual location basis and combined across the 2 environments. The screen house and the field were equated to 2 environments. Data on percentages were angular transformed while those of counts were log transformed before the analysis of variance (Kishore et al., 2007). The mean values of all the traits for each replicate were used to compute the analysis of variance using SAS GLM version 9.2. Treatment means were compared using a protected Fishers' least significant difference (LSD) test at $\mathrm{P}=0.05$. Selection index was calculated based on leaf damage ( $2^{\text {nd }}$ and $4^{\text {th }}$ week $)$, dead heart $\left(2^{\text {nd }}\right.$ and $4^{\text {th }}$ week $)$, stem tunneling and exit holes by adding the ratios between the values for each genotype and the overall mean for each parameter, and divide by 6 (number of damage parameters considered) (Tadele et al., 2011). Genotypes were grouped into four categories namely resistant, moderately resistant, moderately susceptible and susceptible (Tadele et al., 2011, Muturi et al., 2012). The genotypes with selection index values less than 0-0.5 were regarded as resistant, 0.6-1.0 moderately resistance, 1.1-1.5 as moderately susceptible and those with a selection index greater than 2.1 as susceptible (Bergvinson et al., 2004; Tadele et al., 2011 and Muturi et al.,2012).

\section{RESULTS AND DISCUSSION}

There were highly significant $(\mathrm{P}=<0.01)$ differences for seedling vigor, heading date, days to $50 \%$ anthesis, plant height, panicle length, 100 grain weight, grain yield, percentage dead heart at 4 week, percentage leaf damage at 2 week, exit holes and tunnel length among the genotypes tested in the screen house (data not shown). In the field, mean squares due to genotypes were highly significant $(\mathrm{P}=<0.01)$ for all the traits except for dead heart at 2 week and tunnel length (data not shown). For the combined analysis, environment mean squares were significant $(\mathrm{P}=<0.05-0.01)$ differences for all traits except for dead heart at 4 week, exit holes and yield (Table1). There were highly significant $(\mathrm{P}=<0.01)$ differences among genotypes for all traits measured except for leaf damage at 4 weeks, dead heart at 2 weeks and tunnel length. The interactions between environment and genotype were significant for leaf damage at 2 week, dead heart at 2 and 4 weeks but highly significant $(p<0.01)$ for seedling vigor, days to $50 \%$ flowering, plant height, panicle length,100 grain weight and exit hole (Table1).

\section{Mean Performances}

Across the two environments, the mean performance for leaf damage at 2 week ranged from $1.9 \%$ for KAT487 to $52.2 \%$ for Samsorg 17 with a mean of $34.2 \%$. (Table 2). Leaf damage at 4 weeks range from $0.0 \%$ for ICSL71086, ICSR94032 to $48.2 \%$ for Samsorg 3 with an average of $16.2 \%$.Genotypes observed to show low leaf damage at 4 weeks were ICSL71086, ICSR94032, ICSL71268, SSV20041-1 White and ICSB464 (in increasing order of leaf damage incidence). Dead heart at 2 weeks ranged from $0.0 \%$ to $64.8 \%$ with an average of $8.8 \%$. Samsorg 17 recorded the highest number of dead heart $(64.8 \%)$ at 2 weeks. At 4 weeks, it ranged from $0.0 \%$ to $100 \%$ with a mean of $26.5 \%$.Genotypes ICSB 464, ICSV700, ICSL71193, ICSR94030, ICSL71253, ICSL71023 and ICSL71018 suffered the least dead heart damage at 4 weeks. ICSR94032, ICSL71086 and SSV20041-2 Yellow recorded fewer exit holes of 0.5, 1.3 and1.5 respectively. Stem tunneling length range from $10.8 \mathrm{~cm}$ for ICSL71137 to $97.5 \mathrm{~cm}$ for SSV 20041-1 White, with a mean of $49.4 \mathrm{~cm}$.

Seedling vigour scores ranged from 2.0 to 4.0 with an average of 3.0 .Genotypes ICSL71018, ICSL71253, ICSL71268, ICSL71005, SAMSORG 3, SAMSORG 8, SAMSORG17,SAMSORG42 and SAMSORG 44 had greater vigour scores(were more vigorous)than ICSR94030,ICSL71193 and ICSL71061(Table2). Days to panicle emergence (HD) were longest for SAMSORG 17 (92 days) while ICSL71061 took 68 days for the panicle to emerge. The mean heading date observed was 76 days. Days to 50\% flowering ranged from 70 to 94 days for ICSL71061 and SAMSORG 17 respectively with a mean of 78 days. Plant height ranged from $93.8 \mathrm{~cm}$ for ICSL 71137 to $223.4 \mathrm{~cm}$ for Samsorg8 with a mean of $143 \mathrm{~cm}$. Panicle length ranged from $14.2 \mathrm{~cm}$ for ICSV700 to $25,1 \mathrm{~cm}$ for Samsorg8 and closely followed by 
Table 1. Combined means squares for the reaction of sorghum to stemborer (S. calamistis) and agronomic traits.

\begin{tabular}{|c|c|c|c|c|c|c|c|c|c|c|c|c|c|c|c|c|c|}
\hline $\begin{array}{l}\text { Source of } \\
\text { variation }\end{array}$ & $\mathrm{DF}$ & SV & AN & HD & $\begin{array}{l}\text { PLT HT, } \\
\mathrm{cm}\end{array}$ & $\begin{array}{l}\mathrm{PAL}, \\
\mathrm{cm}\end{array}$ & $\begin{array}{l}\text { 100-GW } \\
(\mathrm{g})\end{array}$ & \multicolumn{2}{|r|}{$\begin{array}{l}\text { Yield, } \\
(\mathrm{g}) \\
\end{array}$} & $\begin{array}{l}\text { LD2. }{ }^{\circ} \\
\text { WK }\end{array}$ & $\begin{array}{l}\text { \%LD } 4, \% \\
\text { WK }\end{array}$ & $\begin{array}{l}\mathrm{DH} 2, \% \\
\text { WK }\end{array}$ & \multicolumn{2}{|c|}{$\begin{array}{l}\text { DH, \% E H } \\
4 \mathrm{WK}\end{array}$} & \multicolumn{2}{|c|}{$\begin{array}{l}\mathrm{TL} \\
\mathrm{cm} \\
\end{array}$} & \\
\hline Loc & 1 & $1.16^{* *}$ & $819.9 * *$ & $946.23 * *$ & $25170.6^{* *}$ & $66.04 *$ & $4.33 * *$ & \multicolumn{2}{|c|}{2785.0} & $7.79 * *$ & $0.75 * *$ & $2.27 * *$ & 1.56 & 0.05 & \multicolumn{2}{|c|}{$24951.7 * *$} & \\
\hline Rep (Loc) & 2 & 0.13 & 5.11 & 1.933 & 358.6 & 3.20 & $0.38^{*}$ & \multicolumn{2}{|c|}{1772.0} & 0.02 & 0.04 & $1.80 * *$ & $3.74 * * 0$ & 0.04 & \multicolumn{2}{|c|}{605.4} & \\
\hline $\begin{array}{l}\text { Block } \\
\text { (Loc x Rep) }\end{array}$ & 28 & 0.23 & 3.93 & 3.353 & 318.9 & 5.65 & 0.07 & \multicolumn{2}{|r|}{652.0} & 0.05 & 0.03 & 0.09 & 0.14 & 0.08 & \multicolumn{2}{|c|}{1427.1} & \\
\hline Entry & 87 & $1.58 * *$ & $112.7 * *$ & $115.07 * *$ & $2926.9 * *$ & \multicolumn{2}{|c|}{$45.05 * * 0.99 * *$} & \multicolumn{2}{|c|}{$1537 * *$} & $0.09 * *$ & 0.04 & 0.12 & \multicolumn{4}{|c|}{$0.34 * * 0.15 * * 1077.8$} & \\
\hline Loc x Entry & 87 & $0.64 * *$ & $27.6^{* *}$ & $30.197 * *$ & $1003.7 * *$ & $23.84 * *$ & $0.24 * *$ & & 1067.0 & $0.08^{*}$ & 0.04 & $0.13 *$ & $0.22 * 0$ & $0.10^{*}$ & $* 94$ & & \\
\hline Error & 14 & 0.17 & 3.8 & 2.6414 & 225.4 & 8.16 & 0.08 & & 804.1 & 0.05 & 0.03 & 0.09 & 0.16 & 0.06 & 873 & & \\
\hline \multicolumn{18}{|c|}{ 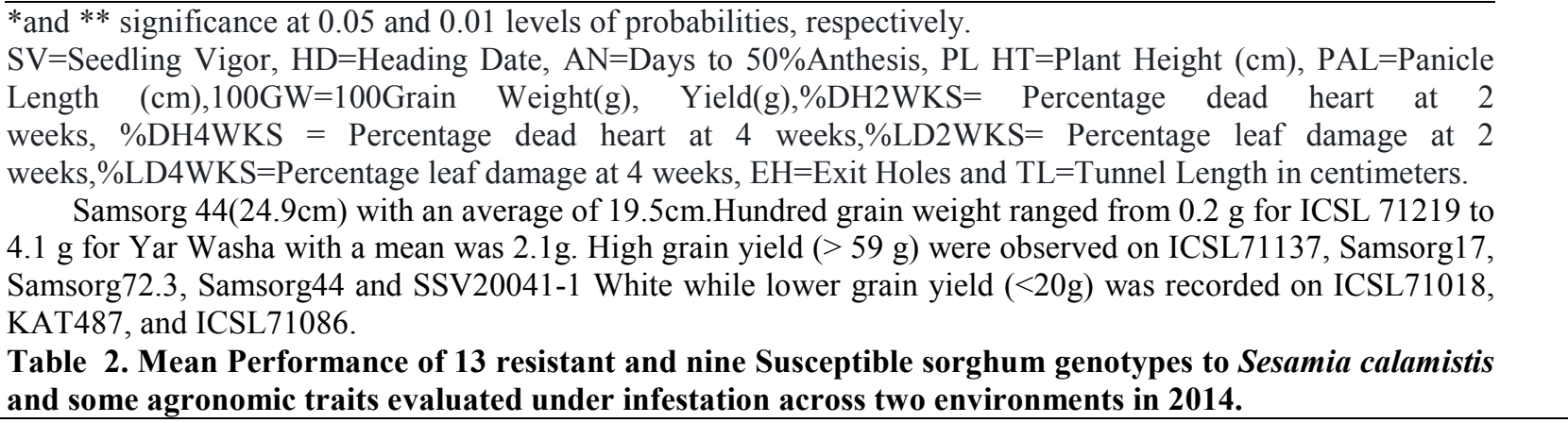 } \\
\hline Line & & $\begin{array}{c}\text { LD2W, } \\
\% \\
2 \mathrm{WK} \\
\end{array}$ & $\begin{array}{c}\text { LD4W, } \% \\
4 \mathrm{WK} \\
\end{array}$ & $\begin{array}{c}\text { DH2W, } \\
\% \\
2 \mathrm{WK} \\
\end{array}$ & $\begin{array}{c}\text { DH4W,\% } \\
4 \mathrm{WK} \\
\end{array}$ & EH & $\begin{array}{l}\text { TL, } \\
\mathrm{cm}\end{array}$ & SI & CAT & SV & HD & AN & $\begin{array}{c}\text { PLANTHT, } \\
\mathrm{cm}\end{array}$ & & $\begin{array}{l}\text { PAL, } \\
\mathrm{cm}\end{array}$ & $\begin{array}{l}\mathrm{GW} \\
, \mathrm{kg}\end{array}$ & $\begin{array}{c}\begin{array}{c}\text { Yield, } \\
\mathrm{kg}\end{array} \\
\end{array}$ \\
\hline ICSB464 & & 28.4 & 5.0 & 0.0 & 0.0 & 2.7 & 29.0 & 0.2 & $\mathrm{R}$ & 3.0 & 81.1 & 81.8 & 125.4 & & 19.8 & 1.8 & 54 \\
\hline $\begin{array}{l}\text { ICSL71086 } \\
\text { SSV20041-2 } \\
\text { YELLOW }\end{array}$ & & $\begin{array}{l}17.2 \\
5.1\end{array}$ & $\begin{array}{l}0.0 \\
8.6\end{array}$ & $\begin{array}{l}0.0 \\
0.0\end{array}$ & $\begin{array}{c}25.4 \\
9.6\end{array}$ & $\begin{array}{l}1.3 \\
1.5\end{array}$ & $\begin{array}{l}20.2 \\
51.0\end{array}$ & $\begin{array}{l}0.2 \\
0.3\end{array}$ & $\begin{array}{l}\mathrm{R} \\
\mathrm{R}\end{array}$ & $\begin{array}{l}3.0 \\
3.0\end{array}$ & $\begin{array}{l}71.9 \\
87.0\end{array}$ & $\begin{array}{l}74.8 \\
88.4\end{array}$ & $\begin{array}{l}100.7 \\
196.5\end{array}$ & & $\begin{array}{l}17.5 \\
17.3\end{array}$ & $\begin{array}{l}2.3 \\
3.0\end{array}$ & $\begin{array}{l}17.7 \\
40.5\end{array}$ \\
\hline ICSL71018 & & 34.6 & 8.6 & 0.0 & 0.4 & 5.8 & 21.7 & 0.3 & $\mathrm{R}$ & 4.0 & 75.6 & 77.8 & 119.5 & & 17.0 & 2.4 & 8.7 \\
\hline ICSR94032 & & 26.7 & 0.0 & 0.0 & 8.7 & 0.5 & 45.5 & 0.4 & $\mathrm{R}$ & 2.0 & 89.0 & 90.1 & 141.9 & & 21.3 & 1.6 & 42 \\
\hline ICSV700 & & 44.1 & 13.0 & 0.0 & 0.0 & 5.2 & 18.2 & 0.4 & $\mathrm{R}$ & 3.0 & 82. & 85.2 & 155.9 & & 14.2 & 1.8 & 34.6 \\
\hline ICSL71193 & & 44.7 & 11.6 & 0.0 & 0.0 & 5.8 & 42.8 & 0.5 & $\mathrm{R}$ & 2.0 & 72.0 & 74.6 & 132.0 & & 19.6 & 2.1 & 29.7 \\
\hline ICSR94030 & & 40.8 & 17.1 & 0.0 & 0.0 & 5.2 & 33.2 & 0.5 & $\mathrm{R}$ & 3.0 & 78.6 & 79.1 & 113.2 & & 24.8 & 1.3 & 31.4 \\
\hline ICSL71253 & & 22.3 & 13.9 & 0.0 & 0.0 & 10.0 & 39.7 & 0.5 & $\mathrm{R}$ & 4.0 & 73.4 & 75.4 & 129.9 & 20.5 & & 2.2 & 33.3 \\
\hline ICSL71268 & & 24.8 & 0.2 & 0.0 & 11.0 & 6.9 & 37.9 & 0.5 & $\mathrm{R}$ & 4.0 & 69.2 & 70.9 & 125.0 & & 15.8 & 1.8 & 43.3 \\
\hline ICSL71023 & & 25.8 & 9.6 & 0.0 & 0.0 & 5.9 & 41.9 & 0.5 & $\mathrm{R}$ & 2.0 & 73.2 & 76.4 & 115.7 & & 17.1 & 2.2 & 41.4 \\
\hline ICSL71061 & & 40.6 & 6.1 & 0.0 & 8.9 & 6.8 & 50.4 & 0.5 & $\mathrm{R}$ & 3.0 & 67.9 & 69.9 & 135.6 & & 17.0 & 1.7 & 22.5 \\
\hline ICSL71137 & & 29.7 & 17.1 & 0.0 & 34.8 & 4.1 & 10.8 & 0.5 & $\mathrm{R}$ & 3.0 & 76.5 & 78.1 & 93.8 & & 15.8 & 1.8 & 59.2 \\
\hline SAMSORG44 & & 37.3 & 9.9 & 32.3 & 49.2 & 6.6 & 53.4 & 1.6 & $\mathrm{~S}$ & 4.0 & 75.9 & 77.5 & 141.7 & & 24.9 & 2.6 & 82.1 \\
\hline $\begin{array}{l}\text { SAMSORG8 } \\
\text { (KSV14) }\end{array}$ & & 34.0 & 28.5 & 28.0 & 59.6 & 3.6 & 26.5 & 1.6 & S & 4.0 & 84.0 & 85.7 & 223.4 & & 25.1 & 3.2 & 72.3 \\
\hline SSV20041-1 WHIT & & 21.6 & 2.2 & 33.0 & 53.4 & 8.2 & 97.5 & 1.6 & $\mathrm{~S}$ & 3.0 & 86.1 & 87.2 & 204.8 & & 22.9 & 3.3 & 90.6 \\
\hline SAMSORG3 (KSV4 & & 38.8 & 48.2 & 28.0 & 47.1 & 4.4 & 45.5 & 1.8 & $\mathrm{~S}$ & 4.0 & 75.3 & 77.4 & 154.7 & & 20.6 & 1.9 & 56.1 \\
\hline ICSL71005 & & 43.3 & 13.9 & 30.6 & 69.7 & 7.3 & 83.5 & 1.9 & $\mathrm{~S}$ & 4.0 & 72.4 & 74.8 & 145.6 & & 20.6 & 1.9 & 31.2 \\
\hline MAIMADARA-2 & & 47.9 & 42.4 & 33.7 & 55.0 & 3.5 & 27.2 & 1.9 & S & 3.0 & 74.8 & 76.0 & 147.3 & & 21.6 & 1.8 & 52.0 \\
\hline SAMSORG42 & & 22.1 & 19.2 & 42.4 & 69.9 & 7.7 & 72.4 & 2.0 & $\mathrm{~S}$ & 4.0 & 88.4 & 90.1 & 163.1 & & 22.3 & 3.1 & 58.9 \\
\hline KAT487 & & 1.9 & 25.1 & 53.8 & 86.2 & 2.8 & 44.6 & 2.1 & $\mathrm{~S}$ & 3.0 & 86.6 & 88.8 & 154.5 & & 24.6 & 2.5 & 16.6 \\
\hline SAMSORG17 & & 52.2 & 22.2 & 64.8 & 100.0 & 3.1 & 57.9 & 2.7 & $\mathrm{~S}$ & 4.0 & 92.2 & 94.1 & 142.7 & & 18.3 & 3.0 & 60.2 \\
\hline Mean & & 34.2 & 16.2 & 8.8 & 26.5 & 5.6 & 49.4 & 1.0 & & 3.3 & 76.1 & 78.0 & 143.0 & & 19.5 & 2.1 & 43.2 \\
\hline $\mathrm{CV}$ & & 51.5 & 84.9 & 229.7 & 95.1 & 50.6 & 59.7 & & & 12.5 & 2.1 & 2.5 & 10.4 & & 14.6 & $\begin{array}{c}13 . \\
3\end{array}$ & 65.7 \\
\hline LSD & & 34.3 & 27 & 39 & 49.3 & 5.6 & 57.9 & & & 0.8 & 3.2 & 3.8 & 29.4 & & 5.6 & 0.5 & 55.6 \\
\hline
\end{tabular}

$\mathrm{SV}=$ Seedling Vigor, $\mathrm{HD}=$ Heading Date, $\mathrm{AN}=$ Days to $50 \%$ Anthesis, PL HT=Plant Height $(\mathrm{cm})$, PAL=Panicle Length $(\mathrm{cm}), 100 \mathrm{GW}=100 \mathrm{Grain}$ Weight $(\mathrm{g})$, Yield $(\mathrm{g}), \% \mathrm{DH} 2 \mathrm{WKS}=$ Percentage dead heart at 2 weeks, $\%$ DH4WKS $=$ Percentage dead heart at 4 weeks, $\%$ LD2WKS $=$ Percentage leaf damage at 2 weeks, $\%$ LD4WKS=Percentage leaf damage at 4 weeks, EH=Exit Holes and TL=Tunnel Length in centimeters

This study identified sorghum genotypes with resistance to $S$. calamistis based on leaf damage, dead heart formation, stem tunneling and exit holes following artificial infestation of seedling whorls with stem borer eggs. Multiple stem borer damage was considered because resistance to stem borers is a multi-mechanism quantitative trait, and thus, selecting for resistance based on a single parameter would not be effective (Singh et al., 2011). Sorghum being an indigenous crop to Africa has co-evolved with native insect pests and it is likely that some varieties are tolerant or resistant to these insect pests (Muturi et al., 2012). The analysis of variance revealed significant variation among the genotypes for all characters examined. Out of the 22 genotypes reported, 13(59\%) of the genotypes with selection index from 0.0 to 0.50 showed resistance across the environment (Table 2). ICSB464, ICSL71086, SSV20041-2YELLOW, ICSL71018, ICSR94032, ICSV700, ICSL71193, ICSR94030, ICSL71253, ICSL71268, ICSL71023, ICSL71061, and ICSL 71137(in an increasing order). Sorghum resistance 
to $C$. partellus based on reduced dead heart damage was reported by Sharma et al., (2006). Genotypes: ICSB464, ICSL71086, ICSL71018, ICSR94032, ICSV700, ICSL71193，ICSR94030，ICSL71268，ICSL71023，ICSL 71137, ICSL71061 and ICSL71253 was previously reported to be resistant to Chilo partellus and Busseola fusca in sorghum (Chinwada et al., 2001; Sharma et al., 2007, Muturi et al., 2012) were also found to be resistant to Sesamia calamistis in this study. This implies that these genotypes have multiple resistance to the three species of stem borers, thus can be used as resistant check in screening trials and as potential donors in the breeding for multiple resistance to the multiple agents of stem borer infection.

Genotypes with selection index 0.60 to 0.10 were ICSV93046, ICSL71077, ICSL71244, ICSR94031, ICSL71258, DALWANDA, ICSL71168, KAURA MAIGUNDUMA, ICSL71180, ICSL71140, YAR GUMEL, ICSB472, ICSL71138, MACIA, ICSL71054, ICSB484, 89MW1005, MORI JIGAWA, SAMSORG6 (KSV12), IS36555, ICSL71219， ICSL71160，SAMSORG14， ICSL71185，ICSL71088， ICSL71247， ICSL71112 AMARYA DA ANGO, and ICSL71085 (data not shown). Out of the 29 moderately resistant genotypes, 6 were elite germplasm: DALWANDA, KAURA MAIGUNDUMA, YAR GUMEL, MACIA, MORI JIGAWA, AMARYA DA ANGO, 2 regional germplasm: 89MW1005, IS36555, and 2 IAR released varieties SAMSORG 6 and SAMSORG14.

Genotypes with selection index 1.1 to 1.5 were: SAMSORG41, KAURA KADUNA-1,ICSL71001, ICSL71055, IS30768,SAMSORG40, RIB*98-SB-F3-78, ICSL71187, ICSV745, SAMSORG5, ICSL71080, FARA 2 BAUCHI, IS17562, ICSL71016,ICSL71213, MAIMADARA-1,ICSL71246, ICSL71215, KL-2, , SAMSORG38, ICSL71007, DANJIBE, RIBDAHU, KL-1,ZAUNA INUWA, TWIN SEEDED, SAMSORG39, SAMSORG17, and YAR WASHA (data not shown).. Some genotypes previously reported as resistant from India (Sharma et al., 2007) and Kenya (Muturi et al., 2012) were found to be moderately susceptible to this pest at the test sites in Nigeria. This could be attributed to the insect species and genotype by environment interactions that influenced expression of resistance to damage by $S$. calamistis.

Genotypes with selection index 1.6 to 2.0 were SAMSORG44,SAMSORG8, SSV20041-1 WHITE, SAMSORG3, ICSL71005,MAIMADARA-2,SAMSORG 42, KAT487 and SAMSORG17.(Table 2). Genotype ICSL71005 previously reported resistant to C. partellus in India (Sharma et al., 2007) and to B. fusca in Zimbabwe (Chinwada et al., 2001), was found susceptible to S.calamitis in Nigeria. This could be attributed to the insect species and genotype by environment interactions.

\section{Conclusion}

This study demonstrated that there are genotypic differences in resistance/susceptibility to damage by $S$. calamistis. Resistance to $S$. calamistis is polygenic, thus, the use of numerous traits facilitate identification of superior genotypes. The sorghum materials could be grouped into resistant, moderately resistant, moderately susceptible and susceptible. This study identified sorghum genotypes with resistance to S. calamistis. The 13 Sorghum genotypes resistant to $S$. calamistis identified can serve as donor parents in the breeding for stem borer resistance. Their use as potential donor parents is further buttressed by the fact that 12 out of the 13 resistant parents possess multiple resistance to the causative agents of stem borer: - Chilo partellus, Busseola fusca and Sesamia calamistis in sorghum. In addition, eight elite germplasm and two IAR varieties were identified to be moderately resistant. Cultivation of genotypes with resistance to stem borers would greatly improve food security and income of the resource poor farmers in areas prone to African pink borer.

\section{Recommendations}

The genotypes identified to have multiple resistance can be used in breeding for multiple resistance to the multiple agents of infection. Genotypes that showed combined resistance to the three borers and with good agronomic performance may be deployed to areas where these borers exist. However, breeding for resistance to these borers should continue besides deployment of these stem borer resistant varieties. The most susceptible genotype, SAMSORG 3, SAMSORG 8, SAMSORG17, SAMSORG 42 and SAMSORG 44 could be utilized as a susceptible check in screening for resistance to $S$. calamistis and improved further to incorporate resistance. The 13 Sorghum genotypes resistant to $S$. calamistis identified can serve as potential donor parents in the breeding for stem borer resistance, also they can be used as resistant check in screening trials. The nine elite germplasm and three IAR varieties identified to be moderately resistant can be capitalized on as takeoff genotypes to build upon their resistance.

\section{ACKNOWLEDGEMENTS}

This study is part of a $\mathrm{PhD}$ research project of the first author conducted with financial support from the Harnessing Opportunities for Productivity Enhancement (HOPE2) Project under the Institute for Agricultural Research (IAR) Plant Science Department, A.B.U, Zaria. We are grateful to Dr C, Tom Hash from ICRISAT India and Dr Mary Mgonja ICRISAT -Nairobi for providing some of sorghum seeds for evaluation .Authors appreciate technical support provided by Mr. Hassan Tush and Ezekiel .Department of Plant Science, Ahmadu 
Bello University Zaria. I also thank The Director General, NABDA, for granting me study leave.

\section{References}

Ajayi O. (1998). Sorghum: West Africa. p. 39-45. In: “African Cereal Stem Borers,Economic Importance, Taxonomy, Natural Enemies and Control" (P. Andrew, ed). CABI in association with the ACPEU. Technical Centre for Agriculture and Rural Cooperation (CTA).

Ajayi, O. (1997). Insecticidal control of the sorghum stem borer. Cereals Research.Programme. Crop. Scheme Rep. Institute for Agric .Research. Samaru, Zaria, Nigeria.

Ajayi, O. (1991). Yield reduction in sorghum caused by Busseola fusca (Fuller) and Sesamia calamistis Hampson. Conf. Afr. Assoc. Insect Sci., 9th, Accra, Ghana.

Amsalu, D., Bekele, J., Melaku, W. (2008). Effect of fertilizer and crop variety on the survival of Busseola fusca (Lepidoptera: Noctuidae) in cereals in Ethiopia. International. Journal of Tropical. Insect Science. 27:172182.

Anaso, C. E. and Thilza, S. (2006). Preliminary study on sorghum stem borer infestation and grain yield as affected by integrating sowing date, seed dressing and cultivar in the Nigerian savanna. Nigerian Journal of Plant Protecton. Vol. 23: 133-140.

Bergvinson D. J., Vasal S. K., Singh N. N., Panwar V. P. S.and Sekhar J. C. (2004). Advances in Conventional breeding for insect resistance in tropical maize, pp. 325-338. In New Technologies for the New Millennium. Proceedings of the 8th Asian Regional Maize Workshop. Bangkok, Thailand, 5-8 August 2002 (edited by G. Srinivasan, P. H. Zaidi B.Prasanna, F. Gonzalez and K. Lesnick). International Maize and Wheat Improvement Center (CIMMYT), Mexico DF.

Chinwada, P, Omwega, C.O, Overholt, W.A. (2001). Stem borer research in Zimbabwe: for the establishment of Cotesia flavipes Cameron. Insect Sci. Appl.21, 327-334 damage and plant resistance. Maydica 39, 203-205

Dhillon, M K, Sharma H C, 2012. Paradigm Shifts in Research on Host Plant Resistance to Insect Pests. Indian Journal of Plant Protection, Volume: 40, Issue: 1 Page: 1-11

Emmanuel, and Chinwe, A. (2008). Influence of Some Inert Diluents of Neem Kernel Powder on Protection of Sorghum against Pink Stalk Borer (Sesamia Calamistis, Homps) In Nigerian Sudan Savanna. Journal of Plant Protection Research.Vol. 48, No. 2 (2008)

Kulman, L.C. (2010). Early-generation germplasm introgression from Sorghum macro Propagation into Sorghum bicolor .53:419-421.

Karaya, H., Njoroge, K., Mugo, S. and Nderitu, H. (2009). Combining Ability among Twenty Insect Resistant Maize inbred lines Resistant to Chilo partellus and Busseola fusca Stem borers. Journal of. Plant Production. 3(1)

Kishore, V., Kumar, K., Dharma, R., Sharma, H.C. (2007). Expression of antixenosis and antibiosis components of resistance to spotted stem borer Chilo partellus in sorghum under greenhouse conditions. $e$ journal.icrisat.org. (3)1.

Kumar, V.K, Sharma, H.C and Reddy, K.D. (2005). Antibiosis component of resistance to stem borer (Chilo partellus) in sorghum, Sorghum bicolor. Crop Prot. 25: 66-72

Liu, G.S., Zhou, Q.Y., Song, S.Q., Jing, H.C., GU, W.B, Li, X.F., Su, M and Srinivasan, R. (2009). Research advances into germplasm resources and molecular biology of the energy plant sweet sorghum. Chin. Bull.Bot. 44, 253-261.

Makueti,J.T,Muturi,P.W,Rubaihayo,P.,Mgonja,M.,Kyamanywa,S.,Kibuka,J.and Sharma,H,C(2012).New sources of resstance to Spotted stem borer,Chilo partellus in Sorghum.International Journal of Agronomy and Agricultural Research(IJAAR).Vol 2(8),pp.18-28

Muturi, P.W, Rubaihayo, P., Mgonja, M., Kyamanywa, S., Sharma, H.C and Hash, C.T, (2012). Novel source of sorghum tolerance to the African stem borer, Busseola fusca. African Journal of Plant Science Vol. 6(11), pp. 295-302

Mwimali, M. Derera, J. Mugo, S. Tongoona, P. (2015) Response to S1 recurrent selection for resistance to two stem borers, Busseola fusca and Chilo partellus, in two tropical maize populations. Euphytica PTO 206:711-723

Sharma, H.C, Dhillon, M.K, Kibuka J, Mukuru, S.Z. (2005). Plant defense responses to sorghum spotted stem borer, Chilo partellus under irrigated and drought conditions. Vol 1 issue 1.e-Journal of SAT Agricultural Research,1(!):3pp

Sharma H.C, Dhillon M.K, Pampapathy G, Reddy BVS. 2007. Inheritance of resistance to spotted stem borer, Chilo partellus in sorghum, Sorghum bicolor. Euphytica 156: 117-128.

Sharma, H.C., Taneja, S.L, Kameswara, Rao, N and Prasada Rao, K. E. (2003). Evaluation of sorghum germplasm for resistance to insect pests. Information Bulletin no. 63. Patancheru 502 324, Andhra Pradesh, India: International Crops Research Institute for the Semi-Arid Tropics. p.184

Singh, B.U, Sharma, H.C, Rao, K.V (2012). Mechanisms and genetic diversity for host plant 
resistance to spotted stem borer, Chilo partellus in sorghum, Sorghum bicolor. J. App Entomology. 136:386400.Importance,

Singh, B.U, Rao, K.V, Sharma, H.C. (2011). Comparison of selection indices to identify sorghum genotypes resistant to the spotted stem borer, Chilo partellus (Lepidoptera: Noctuidae). International Journal of Tropical Insect Science 31(1-2), 38-51.

Singh, B.U. and Rana, B.S. (1986). Influence of varietal resistance on oviposition and larval development of stalk-borer Chilo partellus Swin, and its relationship to field resistance in sorghum. Insect Sci. Appl., 5(4): 287-296.

Tadele, T., Stephen, M., Paddy, L. and Yoseph, B. (2011). Resistance of three-way cross experimental maize hybrids to post-harvest insect pests, the larger grain borer Prostephanus truncatus) and maize weevil (Sitophilus zeamais). International Journal of Tropical Insect Science. 31:3-12.

\section{Authors}

YEYE, Mary is a Professor of Plant Breeding and Genetics in the Faculty of Agriculture, Ahmadu Bello University, Zaria. She holds a Ph.D from the Ahmadu Bello University (2000). Her research is focused on Sorghum Improvement. She has released sorghum varieties along with co-breeders. She is engaged in many collaborative activities with international partners in Sorghum improvement programmes. She is currently working on Developing Stem Borer and Striga Resistant Lines of Sorghum as well Developing Adapted, Suitable and Indigenous A/B pairs for hybrid development

BADIRU, Evilla is the Head of Plant Breeding Unit in the Department of Agricultural Biotechnology at National Biotechnology Development Agency. Abuja, Nigeria

She obtained his first degree in Agriculture Economics and Extension in 1998 at University of Calabar, Master's degree in plant Breeding in 2012 at Ahmadu Bello University Zaria and PhD in Plant Breeding (in view) from Ahmadu Bello University Zaria.

She became a member of the Biotechnology Society of Nigeria, Genetic Society of Nigeria GSN), Nigerian Association of Agricultural Economist (NAAE), Biotechnology Society of Nigeria (BSN), Nigerian Society for Plant Protection (NSPP) and Nigeria Biological Safety Association (NiBSA).

She is currently the Chief Scientific Officer at the National Biotechnology Development Agency. 